\title{
Effect of Educational Intervention on Type II Diabetes Mellitus Control
}

\author{
Mazen Elkurd, Jena Nakata, Burke Voelkel, Mohammad Wadud, Joy H. Lewis \\ A.T. Still University-School of Osteopathic Medicine in Arizona, Mesa, Arizona, USA \\ Email: melkurd@atsu.edu
}

Received 7 February 2014; revised 28 May 2014; accepted 10 June 2014

Copyright (C 2014 by authors and Scientific Research Publishing Inc.

This work is licensed under the Creative Commons Attribution International License (CC BY). http://creativecommons.org/licenses/by/4.0/

c) (i) Open Access

\section{Abstract}

Rural Alabama currently lacks resources to significantly impact the trend of increasing rates of diabetes. Therefore, this pilot study was designed to evaluate the effect of an education intervention on knowledge, motivation, and attitudes of participants with Type II diabetes mellitus. The aim was to improve lifestyle and overall control of diabetes for a rural, vulnerable population. Ten participants ( 7 with diabetes and 3 with pre-diabetes) attended three class sessions over a twomonth period with presentations focused on general diabetes information, diet, exercise, and proper management through glucose measurement and medications. A pre- and post-survey design evaluated participants' behaviors, knowledge, motivation and attitude towards making lifestyle changes. Responses were compared pre- to post-intervention. While knowledge levels related to diabetes, diet, and exercise increased, the changes were not statistically significant. Similarly, participants expressed increased motivation towards weight loss, healthful eating, exercise and positive lifestyle choices. However, these changes were not statistically significant. This pilot study demonstrates an increase in personal knowledge, motivation, and attitude for a small group of patients with diabetes or pre-diabetes. These group classes are inexpensive and will be easy to replicate with larger groups. They demonstrate the potential to motivate patients towards positive change.

\section{Keywords}

Diabetes, Education, Motivation, Behavior

\section{Introduction}

In 2011, there were 18.8 million people diagnosed with diabetes mellitus, ranking as the seventh leading cause of death in the US [1]. An overwhelming majority at 90\% are Type II diabetics [2]. Type II diabetes leads to 
complications of blindness, renal failure, and amputations with comorbidities of heart, strokes, and peripheral vascular disease [3].

Alabama has one of the highest rates of Diabetes in the United States. There is almost twice the percentage of diabetics in Alabama and its rural Pike county compared to the national average [4]-[6]. Thus the rural Pike county of Alabama, where this pilot study was completed, is a sufficient area to study Type II diabetics. In addition, rural residents are shown to have longer life expectancy. However they also have more years living with impairment due to chronic diseases such as diabetes [7]. This could be changed through increased knowledge, motivation, and positive attitude to a healthier life.

A multidisciplinary approach with more information on medications, the disease, and support by multiple professionals has been shown to improve the outcome and glucose control of patients with Type II diabetes [8]. Norris and colleagues conducted a systematic review of the literature and found that studies suggest that in the short term education programs aimed towards improving patient's knowledge related to diabetes self-care resulted in improved self-monitoring of glucose and positive dietary changes. Further, aerobic exercise has been proven to significantly lower HbA1c levels, increase insulin sensitivity, and improve cardiovascular risk factors [9].

Many studies have shown diabetes knowledge, healthy diet changes and exercise improve diabetic's disease. However, only 35\% of the US diabetic population in 1994 had a formal educational on diabetes [10].

Ultimately, this pilot study developed a series of education interventions for Type II diabetes focusing on 3 aspects: basic diabetes information, diabetic diet, and exercise for diabetes. The study evaluated the intervention using a pre- and post-survey design to assess whether the interventions improved participant motivation, knowledge, and attitudes towards making lifestyle changes to help control their diabetes.

\section{Methods}

Volunteer participants were recruited from two senior activities centers in Troy Alabama and the vicinity. Entry criteria were that the participants needed to have a diagnosis of diabetes or "pre-diabetes". Pre-diabetes was defined as those with a fasting blood glucose level from $100 \mathrm{mg} / \mathrm{dL}$ - $125 \mathrm{mg} / \mathrm{dL}$ (diagnoses self-reported by participants) [11]. In addition, participants could not have previously been part of a Diabetes education class.

The volunteer participants completed a pre-survey to evaluate baseline levels of motivation, knowledge and attitudes towards lifestyle changes to control their diabetes (or pre-diabetes).

Participants attended a series of three 40-minute educational interventions once a week for three consecutive weeks. Education materials were adapted from the American Diabetic Association (ADA) and focused on general diabetes information, diabetic diet, and proper exercise techniques. All lifestyle changes and activities suggested during teaching were ensured to be appropriate for the audience and compliant with ADA guidelines ensuring participants' safety.

A modified version of the Personal Diabetes Questionnaire (PDQ) developed by the University of Louisville [12] [13] was used to assess participants' current actions relating to diabetes pre-and post-intervention. Four questions were added to the post-intervention questionnaire to assess participants' knowledge, attitude and motivations post-intervention. The PDQ has been proven to be a valid and effective tool for assessing Type I and Type II diabetics' behaviors and perceptions to their diseases (Figure 1).

After the intervention, the participants were asked four questions to assess subjective changes in their motivation, attitudes and knowledge.

\section{Results}

Table 1 demonstrates 10 patients were enrolled in the study. Five males, 5 females, 7 with diabetes, 3 with prediabetes. All participants were over age 65 .

Table 2 demonstrates there was an improvement in the participant responses relating to their current actions regarding glucose control, diet and exercise. However, these changes were not statistically significant. The responses for each question asked pre- and post intervention were quantified based on a numerical scale from 1 - 5 based on the five answer choices for each question. The sum of all responses were then tallied and compared.

Participants were asked the question: "Are you actively trying to lose weight?”

There was an increase in the number participants responding "Yes". Before the classes began, 3 participants answered "Yes", after attending the sessions 4 participants answered "Yes" to this question. The number of participants responding "No, but trying to keep from gaining weight," remained the same at 5. 
As demonstrated in Table 3, we posed four additional questions to the participants post-intervention. The first question asked was "Do you feel these classes have motivated you to improve you food choices relating to diabetes?" Of the ten total participants, four responded "Yes" and six reported "Likely".

Participants were next asked: "Do you feel that these classes have helped improve your attitude to making better lifestyle choices related to diabetes?" Six of the ten reported "Yes" and four reported "Likely".

In response to the question "Do you feel you have learned and understood information in these classes to help you make better lifestyle choices?

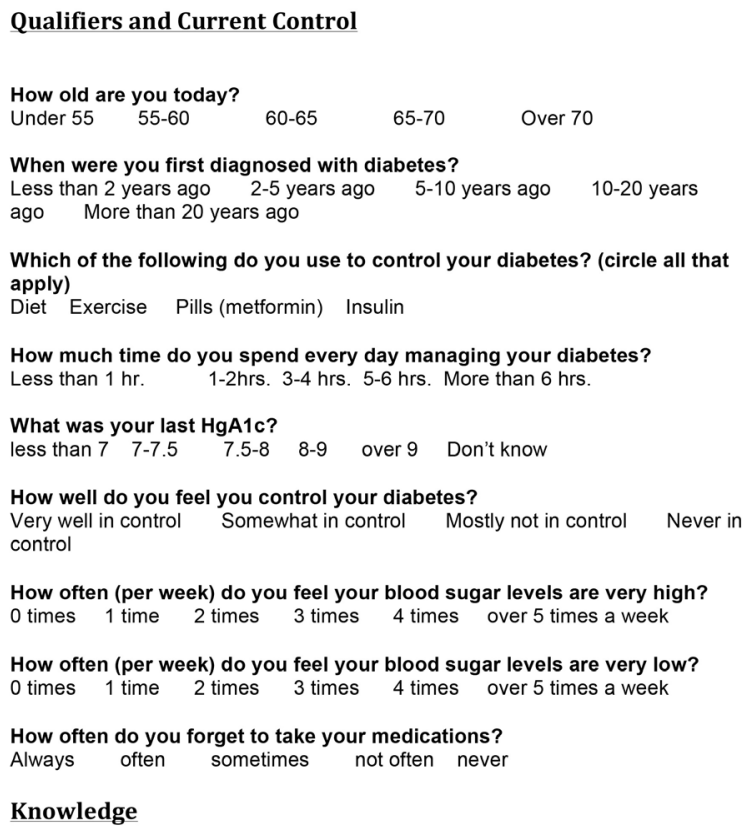

\section{Obstacles}

How often do you find difficulty taking your medications?

How often does transportation play a role in obtaining your prescriptions and glucose testing supplies?

Always often sometimes not often never

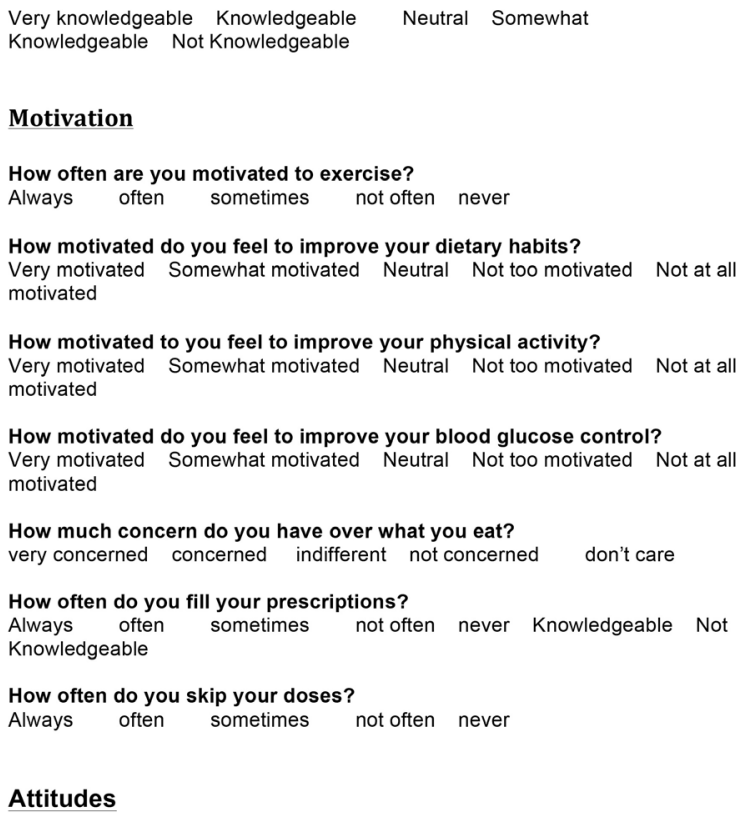

How optimistic do you feel about being able to control your blood sugar? Very optimistic Optimistic Neutral Somewhat Optimistic Not Optimistic

How do you think improving your blood sugar control would impact your quality of life?

Improve Slightly Improve No Change Slightly Worsen Worsen

How often do you take into account the control of your blood sugar when making a dietary choice?

Always often sometimes not often never

Figure 1. Assessment tool used for the study.

Table 1. Description of study participants.

\begin{tabular}{ccc}
\hline & Diabetics & Pre-Diabetics \\
\hline Male & 4 & 1 \\
Female & 3 & 2 \\
\hline
\end{tabular}


Table 2. Mean sum of responses on questionnaire pre and post intervention.

\begin{tabular}{ccccc}
\hline Participants Included: & $\begin{array}{c}\text { Mean Sum of Response } \\
\text { Pre-Intervention }\end{array}$ & $\begin{array}{c}\text { Mean Sum of Response } \\
\text { Post-Intervention }\end{array}$ & P-Value & $\begin{array}{c}\text { Critical T-Value } \\
\text { (5\%) }\end{array}$ \\
\hline Diabetes and Prediabetes & 28.2 & 30.5 & 0.242 & 2.31 \\
Diabetes Only & 32.4 & 32.6 & 0.941 & 2.57 \\
Prediabetes Only & 19.7 & 26.3 & 0.081 & 4.30 \\
\hline
\end{tabular}

Table 3. Responses to post-intervention only questions.

\begin{tabular}{|c|c|c|c|}
\hline & $\begin{array}{l}\text { Participants } \\
\text { Answering No: }\end{array}$ & $\begin{array}{l}\text { Participants Who Answered } \\
\text { Likely or They Have } \\
\text { Learned a Few Things: }\end{array}$ & $\begin{array}{l}\text { Participants } \\
\text { Answering Yes: }\end{array}$ \\
\hline $\begin{array}{l}\text { Do you feel these classes have motivated you to } \\
\text { improve you food choices relating to diabetes? }\end{array}$ & 0 & 6 & 4 \\
\hline $\begin{array}{l}\text { Do you feel that these classes have helped } \\
\text { improve your attitude to making better lifestyle } \\
\text { choices related to diabetes? }\end{array}$ & 0 & 4 & 6 \\
\hline $\begin{array}{l}\text { Do you think you will make more time for } \\
\text { exercise or physical activity after attending these } \\
\text { classes on diabetes? }\end{array}$ & 1 & 5 & 4 \\
\hline $\begin{array}{l}\text { Do you feel you have learned and understood } \\
\text { information in these classes to help you make } \\
\text { better lifestyle choices? }\end{array}$ & 0 & 6 & 4 \\
\hline
\end{tabular}

Four of the ten participants responded "Yes" and six reported "Maybe."

Finally, the participants were asked "Do you think you will make more time for exercise or physical activity after attending these classes on diabetes?

Of the ten, four reported "Yes", five reported "Likely" and one reported "No".

\section{Discussion}

This research demonstrates that the participants in three education sessions increased their motivation, attitude, and knowledge of diabetes and healthier lifestyle choices. While their survey scores did not have a statistically significant change from pre- to post-survey, the responses were overwhelmingly positive.

The limitations of this study include the short duration, small sample size and difficulty achieving behavior changes of exercise for the elderly population.

There was no statistically significant change shown in the questions evaluating participants' current actions pre- and post-intervention, which could have been affected by the small sample size. Also, the short duration of the study may not have allowed adequate time for participants to implement changes they are positively motivated towards.

Future research should employ a longer intervention period and a third questionnaire to assess changes in behavior over time. Additionally, larger sample sizes could improve the chance of achieving statistically significant results.

We would also suggest attempting to recreate this study on a group with fewer physical limitations. Many of the study participants experienced physical restrictions preventing them from exercising.

This was a small pilot study of an educational intervention. The results of this study cannot be generalized beyond the participants. Instead, this study provides a description of an intervention that demonstrated potential to improve knowledge and motivation for a vulnerable population.

\section{Conclusion}

Community Health Centers (CHCs) in the United States are a network of federally-funded, community managed primary health centers that provide a safety net for the nation's uninsured and underinsured [14]. These centers typically provide a wide-range of services, including but not limited to primary care. CHCs adjust their charges to the patient's income. As a result, these centers typically treat a significant number of patients with diabetes 
and those at risk for diabetes. This is a large and growing segment of the population, projected to be up to 44 million people by 2015 [15]. Although this study did not show statistically significant difference in the survey responses, the follow-up questions showed that most participants perceived that they gained knowledge regarding diabetes and how to properly manage it. Due to the limited amount of resources required to implement such a program, this educational intervention model could easily be applied in community health centers around the nation. The only resources required would be for a clinical team to set up a number of educational workshops and for a qualified professional to deliver the material to the patients.

\section{References}

[1] Centers for Disease Control and Prevention (2009) County Level Estimates of Diagnosed Diabetes of Adults in Alabama, 2009. http://apps.nccd.cdc.gov/DDT_STRS2/CountyPrevalenceData.aspx?mode=DBT

[2] Centers for Disease Control and Prevention (2011) National Diabetes Fact Sheet: National Estimates and General Information on Diabetes and Prediabetes in the United States, 2011. US Department of Health and Human Services, Centers for Disease Control and Prevention, Atlanta. http://www.cdc.gov/diabetes/pubs/pdf/ndfs_2011.pdf

[3] World Health Organization (1999) Definition, Diagnosis and Classification of Diabetes Mellitus and Its Complications. http://www.staff.ncl.ac.uk/philip.home/who dmc.htm

[4] United States Census Bureau (2011) Pike County, Alabama People Quick Facts. http://quickfacts.census.gov/qfd/states/01/01109.html

[5] The Henry J. Kaiser Family Foundation (2011) Alabama: Diabetes Percent of Adults Who Have Ever Been Told by a Doctor That They Have Diabetes. http://www.statehealthfacts.org/profileind.jsp?sub=22\&rgn=2\&cat=2

[6] Alabama Department of Public Health (2010) Diabetes in Alabama. http://adph.org/diabetes/assets/DiabetesinALReport09.pdf

[7] Laditka, J.N., Laditka, S.B., Olatosi, B. and Elder, K.T. (2007) The Health Trade-Off of Rural Residence for Impaired Older Adults: Longer Life, More Impairment. The Journal of Rural Health, 23, 124-132.

http://dx.doi.org/10.1111/j.1748-0361.2007.00079.x

[8] Medical Advisory Secretariat (2009) Community-Based Care for the Management of Type 2 Diabetes: An EvidenceBased Analysis. Ontario Health Technology Assessment Series, 9. http://www.ncbi.nlm.nih.gov/pubmed/23074528

[9] Zanuso, S., Jimenez, A., Pugliese, G., Corigliano, G. and Balducci, S. (2010) Exercise for the Management of Type 2 Diabetes: A Review of the Evidence. Actadiabetologica, 47, 15-22. http://dx.doi.org/10.1007/s00592-009-0126-3

[10] Coonrod, B.A., Betschart, J. and Harris, M.I. (1994) Frequency and Determinants of Diabetes Patient Education among Adults in the US Population. Diabetes Care, 17, 852-858. http://dx.doi.org/10.2337/diacare.17.8.852

[11] World Health Organization (2006) Definition and Diagnosis of Diabetes Mellitus and Intermediate Hyperglycaemia. http://whqlibdoc.who.int/publications/2006/9241594934_eng.pdf

[12] Stetson, B., Schlundt, D., Rothschild, C., Floyd, J.E., Rogers, W. and Mokshagundam, S.P. (2011) Development and Validation of the Personal Diabetes Questionnaire (PDQ): A Measure of Diabetes Self-Care Behaviors, Perceptions and Barriers. Diabetes Research and Clinical Practice, 91, 321-332. http://dx.doi.org/10.1016/j.diabres.2010.12.002

[13] Stetson, B. (2011) Personal Diabetes Questionnaire. Department of Psychological and Brain Sciences, University of Louville, Louville. http://louisville.edu/psychology/stetson/lab/personal-diabetes-questionnaire

[14] Taylor, J. (2004) The Fundamentals of Community Health Centers. The George Washington University, Washington DC.

[15] Kaiser Commission on Medicaid and the Uninsured (2010) Community Health Centers: Opportunities and Challenges of Health Reform. http://www.kff.org/uninsured/upload/8098.pdf 